\title{
COMPARATIVE STUDY OF FOUR LEGGED SELF-SUPPORTED ANGULAR TELECOMMUNICATION TOWER ON GROUND AND MOUNTED ON ROOF TOP
}

\author{
C Preeti $^{1}$, Sankara Ganesh Dhoopam ${ }^{2}$ \\ ${ }^{1}$ Assistant Professor, Department of Civil Engineering, GRIET, Telengana State, India \\ ${ }^{2}$ Head of Engineering Services, RAMBOLL India Telecom, Telengana State, India
}

\begin{abstract}
Due to increase in demand, huge number of telecommunication towers has been built in India during last few decades with the compulsion to provide efficient communication. Consequently, telecommunication sector in the country has expanded rapidly. Expanding base possesses challenges to mobile operators in terms of augmenting and upgrading infrastructure to uphold to excellence of services. A rapidly rising subscriber and a more rigorous band allocating organization may create a higher requirement of tower sites for operators to accommodate more subscribers. Hence it became an expensive and tedious task to spot ample land for construction of towers. This led to the extensive use of the rooftop of multi-storeyed buildings for installing communication towers.

Formerly the majority of the buildings were not cautious to carry a roof top tower, however owing to the altered needs; buildings were rehabilitated to carry roof top towers. In this report analysis of 4 legged angular self-supporting telecommunication towers is performed. Assessment is done based on modal analysis, by comparing the results of roof top tower and ground based tower. In support of this intention, two 4 legged self-supporting telecommunication towers of $24 \mathrm{~m}$ and $21 \mathrm{~m}$ are modeled on roof top of a building and on the ground, considering the effects of wind loads as per Indian condition. Effects of wind on towers are employed from the IS 875 (Part 3)-1987 by using STAAD pro finite element software. The tower and building is analysed by placing towers at centre of roof. Axial forces experienced by the structures too have been obtained
\end{abstract}

Keywords: telecommunication tower, roof top, ground based, dynamic analysis

\section{INTRODUCTION}

Telecommunication towers have become an indispensable thing particularly in wireless telecommunication sector with the expansion of wireless telecommunication technologies such as CDMA (Code Division Multiple Access), GSM (Global System for Mobile), and WAP (wireless Web Access). In the human civilization at the moment the telecommunication structures are elementary mechanism of communication. Post-disaster network and their protection in the case of not only a severe tremor but moreover to locations experiencing the far field effects are critical. Telecommunication towers are characteristically tall structures whose purpose is to sustain elevated antennas for radio and television broadcasting, telecommunication and two-way radio systems. In addition, performance of infrastructure such as dams, electric, gas, and fuel transmission stations, depends extensively on the data being transmitted by means of these telecommunication towers. Other areas of application for such towers are military and defence industries in addition to television, radio, and telecommunication industries and thus creates the necessity for further research. For that reason, abrupt serviceability or constant function of first-aid-station infrastructure is of crucially main concern in the case of a disaster. Because of their inimitable geometry, telecommunication towers are categorised as slender-tall multi-support structures. Amiri et.al (2004) established that owing to their imperative role, the safeguarding of these telecommunication structures during a natural disaster such as an earthquake is of paramount priority and that's why their dynamic analysis should be accurately evaluated.

The structural engineer faces the tough job of designing and constructing telecommunication towers to bear antenna loads, platform over and above steel ladder loads in open weather with high degree of consistency. High intensity winds (HIW) remains the foremost cause of malfunction of telecommunication tower all over the world. The key crisis faced is the complexity in estimating wind loads as they are based on a probabilistic approach. There have been numerous studies in telecommunication towers taking into consideration the wind as well as dynamic effect. Amiri and Booston (2002) studied the dynamic response of antennasupporting structures. In this view, self-supporting steel telecommunication towers with different heights were evaluated considering the wind and earthquake loads. An assessment is made between the results of wind and earthquake loading.

Richa Bhatt et al. (2013) have carried out study on the influence of modelling in lattice mobile towers in wind loading where in the towers are analysed for gust factor wind. Displacements, member forces and maximum stress 
have been compared to find out the effect on towers. Siddesha. H (2010), carried out the wind analysis on antenna towers with static \& gust factor method, the displacements at the top of the tower with angle and square sections are considered.

Self-supporting telecommunication towers are three-legged or four-legged space trussed structures with typical heights between $30 \mathrm{~m}$ and $160 \mathrm{~m}$. They consist of main legs and horizontal and vertical bracing members. Main legs are in general made of $90^{\circ}$ angles in four-legged towers and $60^{\circ}$ angles in three legged towers. The most familiar brace patterns are the chevron and the X-bracing. Generally, lattice towers are built on rigid ground, nevertheless because of space constraints in urban areas and to evade huge and pricey constructions; they are sometimes mounted on building rooftops. The availability of land which satisfies best installation conditions in urban areas is awfully restricted giving no substitute but to implement roof top towers (with minor adjustment in position but not in height). Hence, these towers are usually shorter than those built on ground.

Chiu and Taoka (1973) were amongst the first to carry out an experimental and theoretical study on the dynamic response of lattice self-supporting telecommunication towers under real and simulated wind forces. A 3-legged $46 \mathrm{~m}$ self-supporting telecommunication tower was investigated in their research, for its dynamic response under wind loading. The study showed that the tower response to wind-induced forces was dominated by the fundamental mode of vibration. Additionally, the average damping for the fundamental mode was obtained to be $0.5 \%$ of the critical viscous damping value, which is considered to be very low.

Venkateswarlu et al. (1994) performed a numerical study on the response of lattice microware towers subjected to random wind loadings. The dynamic response is estimated by the use of a stochastic approach. For evaluating the along-wind response and the consequent gust response factor a spectral analysis method were introduced. The ratio of the expected maximum wind load effect in a specified time period to the corresponding mean value in the same time period is gust response factor. A 4-legged $101 \mathrm{~m}$ selfsupporting tower was considered in their study. The gust response factor along the tower height was calculated with and without the contributions of second and higher modes of vibration. The outcome showed a maximum of $2 \%$ change in the gust factor when employing higher modes of vibration.

In the current study, the dynamic response of 4-legged angular self-supporting telecommunication tower has been done. The comparison has been made between rooftop tower and ground tower. The towers are subjected to wind load analysis for more practical dynamic response. Numerical simulation is done to study the response of two selfsupporting telecommunication lattice towers of heights of 21 $\mathrm{m}$ and $24 \mathrm{~m}$, mounted on the rooftop of two commercial buildings of $16 \mathrm{~m}$ and $21 \mathrm{~m}$ height. Both are modeled as linear elastic, three-dimensional frame structures. The supports are fixed at the base. The mass of the towers is considered, with the provision for antennas and other tower accessories. This study rely exclusively an on numerical experiment that is comprehensive three dimensional full scale simulation using FEM.

\section{NUMERICAL MODELLING CONSIDERATIONS}

\subsection{Wind loads}

On a lattice structure like tower; vertical uplift, downward thrust, and drag force are the three wind force effects that were measured. Based on the configuration of the tower, 0 degree and 45 degree wind directions are considered (square tower). Dead load + zero degree direction basic wind speed, and Dead load +45 degree direction basic wind speed load combination is used for analysis of tower
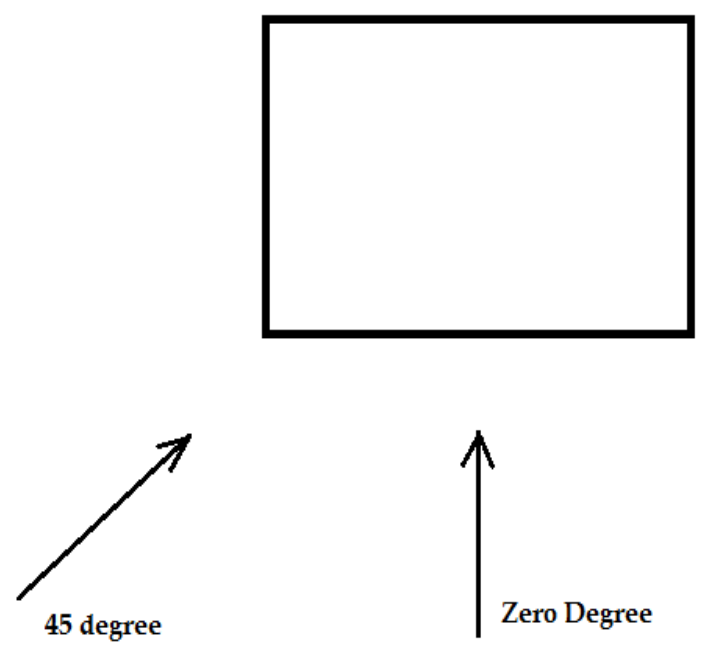

Figure 1 Wind load direction on square towers

The wind load on tower is computed according to the Indian standards IS: 875(Part 3)-1987. The basic wind speed depending on the location of tower is selected as $44 \mathrm{~m} / \mathrm{s}$ (for Hyderabad region). Other parameters for instance terrain category is taken as 2 and Class B, mean probable life as 100 years, probability factor as 1.07 , Topography Factor as 1 , and tower height + building height should not exceed $40 \mathrm{~m}$ AGL for all tower height. The design wind speed is modified to induce the effect of risk factor $\left(\mathrm{k}_{1}\right)$, terrain coefficient $\left(\mathrm{k}_{2}\right)$ and local topography $\left(\mathrm{k}_{3}\right)$ to get the design wind speed $\mathrm{V}_{\mathrm{z}}$,

$\mathrm{V}_{\mathrm{z}}=\mathrm{V}_{\mathrm{b}} \times \mathrm{K}_{1} \times \mathrm{K}_{2} \times \mathrm{K}_{3}$

- Eq. 1

The design wind pressure $\mathrm{P}_{\mathrm{z}}$ at any height above mean ground level is,

$\mathrm{P}_{\mathrm{z}}=0.6 \times \mathrm{V}_{\mathrm{z}}^{2}$

The coefficient 0.6 in the above formula depends on a number of factors and mainly on the atmospheric pressure and air temperatures. The wind load acting on a tower is computed as

$\mathrm{F}_{\mathrm{z}}=\mathrm{C}_{\mathrm{f}} \times \mathrm{Ae} \times \mathrm{P}_{\mathrm{Z}}$

- Eq. 3

\subsection{Tower Modelling Assumptions}

Owing to the existence of numerous members and the range of cross-sections in such structures, the computer software used should be capable of apt graphical competence, with the intention that a rapid and accurate numerical 
configuration could be defined. Effortless access to the input and output data is also considered necessary. On these bases, STAAD Pro, among the existing structural programs, was chosen for analysis.

For the simulations, two self-supporting 4 legged steel telecommunication towers, usually built on ground are considered which have been designed, fabricated and erected on the basis that wind forces were the dominant design forces. Square transversal cross section cross bracing is utilized in each tower. Tower M24 is $24 \mathrm{~m}$ tall and Tower M21 is $21 \mathrm{~m}$ tall. The towers have been idealized as space frame and were modeled using frame element. The descriptions of the towers are listed in Table 1 and Table 2. A general view of their model geometry is shown in Figure 2.

Table 1 Section details of Tower M24 (in m)

\begin{tabular}{|l|l|}
\hline Height of tower & 24.00 \\
\hline Height of straight portion at top of the tower & 12.00 \\
\hline Height of slant portion & 12.00 \\
\hline Effective base width & 2.86 \\
\hline Effective top width & 1.30 \\
\hline
\end{tabular}

Table 2 Section details of Tower M21 (in m)

\begin{tabular}{|l|l|}
\hline Height of tower & 21.00 \\
\hline $\begin{array}{l}\text { Height of straight portion at top of the } \\
\text { tower }\end{array}$ & 12.00 \\
\hline Height of slant portion & 12.00 \\
\hline Effective base width & 2.86 \\
\hline Effective top width & 1.30 \\
\hline
\end{tabular}
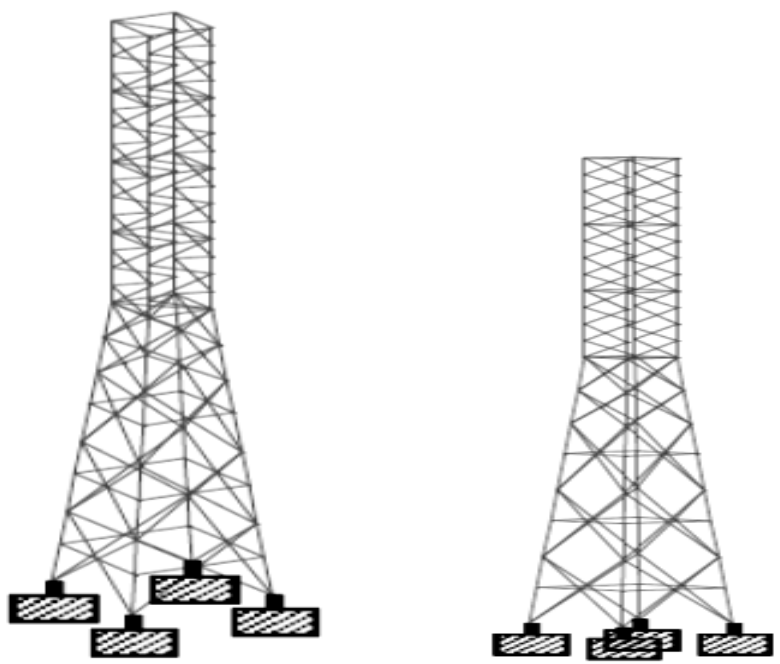

Figure 2 Geometry of model tower M24 and tower M21

All steel members are validated to mild steel material as per IS: 2062-200 (Minimum yield stress 250Mpa and Allowable bearing stress $500 \mathrm{Mpa}$ ). All structural bolts are validated to 5.6 grade as per IS: 12427-2000 (Minimum yield stress $310 \mathrm{Mpa}$ and Allowable bearing stress 620Mpa).

The location of tower on rooftop is generally decided based on utility of remaining space. However this may lead to unfavourable conditions with respect to the structural behaviour. So towers are modelled at the central portion of the building.

Table 3: Angle sections of $24 \mathrm{~m}$ tower

\begin{tabular}{|c|c|c|c|c|c|c|c|c|c|}
\hline Panel no. & $\mathbf{1}$ & $\mathbf{2}$ & $\mathbf{3}$ & $\mathbf{4}$ & $\mathbf{5}$ & $\mathbf{6}$ & $\mathbf{7}$ & $\mathbf{8}$ & $\mathbf{9}$ \\
\hline Main leg & $130 \times 130$ & $110 \times 110 \times 10$ & $100 \times 100 \times 10$ & $100 \times 100 \times 10$ & $100 \times 100 \times 10$ & $100 \times 100 \times 8$ & $90 \times 90 \times 6$ & $75 \times 75 \times 5$ & $75 \times 75 \times 5$ \\
\hline Horizontal & - & - & - & - & $45 \times 45 \times 5$ & $45 \times 45 \times 5$ & $45 \times 45 \times 5$ & $45 \times 45 \times 5$ & $45 \times 45 \times 5$ \\
\hline Diagonal & $45 \times 45 \times 4$ & $45 \times 45 \times 4$ & $45 \times 45 \times 4$ & $45 \times 45 \times 5$ & $45 \times 45 \times 5$ & $50 \times 50 \times 5$ & $50 \times 50 \times 5$ & $45 \times 45 \times 5$ & $45 \times 45 \times 5$ \\
\hline
\end{tabular}

Table 4: Details of bolts

\begin{tabular}{|c|c|c|c|c|c|c|c|c|c|}
\hline Main leg & $\begin{array}{c}\text { 130x130x10 } \\
8 \mathrm{M} 16 \text { DS }\end{array}$ & $\begin{array}{c}\text { 110x110x10 } \\
6 \mathrm{M} 16 \text { DS }\end{array}$ & $\begin{array}{c}100 \times 100 \times 10 \\
6 \mathrm{M} 16 \mathrm{DS}\end{array}$ & $\begin{array}{c}100 \times 100 \times 10 \\
6 \mathrm{M} 16 \text { DS }\end{array}$ & $\begin{array}{c}100 \times 100 \times 10 \\
6 \mathrm{M} 16 \text { DS }\end{array}$ & $\begin{array}{c}\text { 100x100x8 } \\
6 \mathrm{M} 16 \mathrm{DS}\end{array}$ & $\begin{array}{l}90 \times 90 \times 6 \\
6 \mathrm{M} 16 \mathrm{DS}\end{array}$ & $\begin{array}{l}75 \times 75 \times 5 \\
4 \mathrm{M} 16 \mathrm{DS}\end{array}$ & $\begin{array}{c}75 \times 75 \times 5 \\
2 \mathrm{M} 16 \text { DS }\end{array}$ \\
\hline Horizontal & - & - & - & - & $\begin{array}{c}45 \times 45 \times 5 \\
2 \mathrm{M} 16\end{array}$ & $\begin{array}{c}45 \times 45 \times 5 \\
2 \mathrm{M} 16\end{array}$ & $\begin{array}{c}45 \times 45 \times 5 \\
2 \text { M16 }\end{array}$ & $\begin{array}{c}45 \times 45 \times 5 \\
2 \mathrm{M} 16\end{array}$ & $\begin{array}{c}45 \times 45 \times 5 \\
2 \mathrm{M} 16\end{array}$ \\
\hline $\begin{array}{c}\text { All } \\
\text { Redundant }\end{array}$ & $1 \mathrm{M} 16$ & & & & & & & & \\
\hline
\end{tabular}




\subsection{Building Models}

\section{a) Building B16}

The first building is B16 has a rectangular plan of $32.86 \mathrm{~m} \mathrm{x}$ $27.86 \mathrm{~m}$. It is a $7 \times 6$ bays building, with a total height is $16 \mathrm{~m}$, with the first floor built at ground level.

Table 5 Description of Building B16 (Preliminary Data)

\begin{tabular}{|c|c|}
\hline Number of Storey's & 5 \\
\hline Beam Size & $300 \mathrm{~mm}$ x 350 mm \\
\hline Column Size & $300 \mathrm{~mm} \times 350 \mathrm{~mm}$ \\
\hline Floor Height & $\begin{array}{c}\text { each floor of } 3 \mathrm{~m}(\text { except } \\
\text { ground floor of 4m) }\end{array}$ \\
\hline
\end{tabular}

Material Properties: Concrete - M15 grade, Compressive strength of concrete (fck) $=15 \mathrm{~N} / \mathrm{mm}^{2}$, Modulus of Elasticity $\left(E_{c}\right)=5000 \sqrt{ }$ fck N/mm 2 , Steel $-\mathrm{Fe}$ 415 grade, Yield stress $\left(f_{\mathrm{y}}\right)=415 \mathrm{~N} / \mathrm{mm}^{2}$

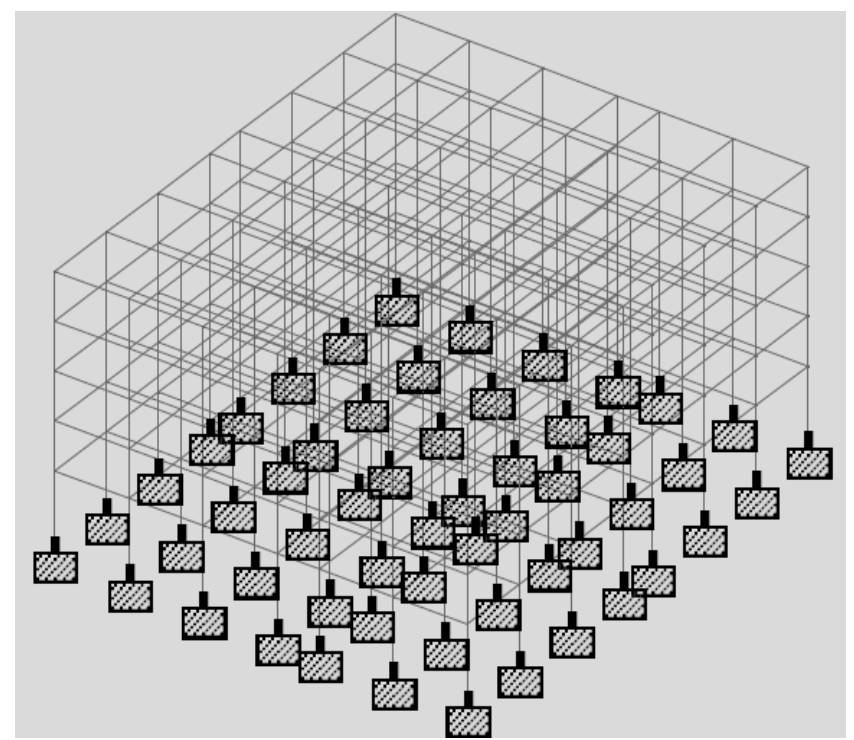

Figure 3 Building B16 modeled in STAAD Pro.

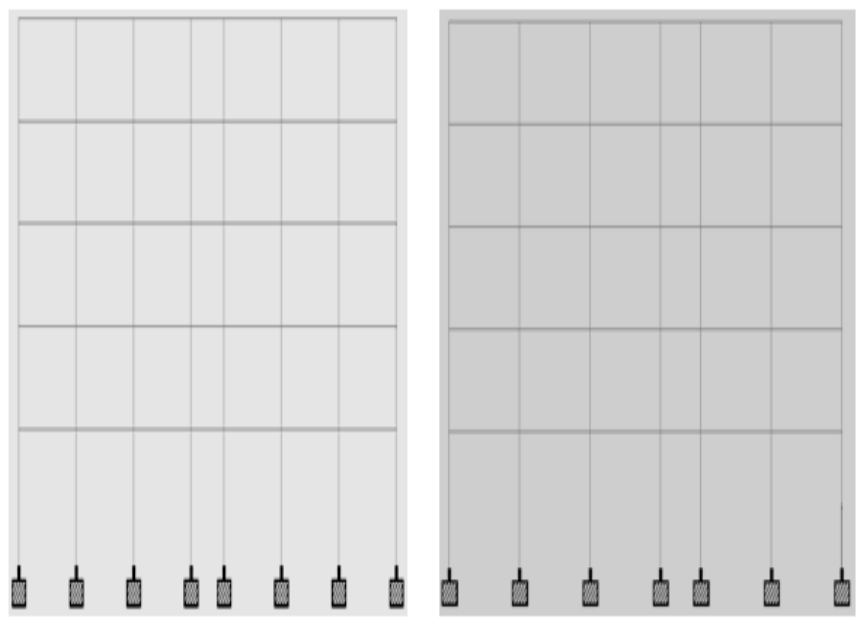

Figure $4 \mathrm{X}-\mathrm{Y}$ and Z-Y projections of Building B16

\section{b) Building B21}

The building B21 has a rectangular plan of $32.86 \mathrm{~m}$ x 37.86 $\mathrm{m}$ and a total height of $21 \mathrm{~m}$.

Table 6 Description of Building B16 (Preliminary Data)

\begin{tabular}{|l|l|}
\hline Number of Storey's & 7 \\
\hline Beam Size & $350 \mathrm{~mm}$ x $300 \mathrm{~mm}$ \\
\hline Column Size & $50 \mathrm{~mm}$ x $300 \mathrm{~mm}$ \\
\hline Floor Height & $3 \mathrm{~m}$ \\
\hline
\end{tabular}

Material Properties: Concrete - M15 grade, Compressive strength of concrete (fck) $=15 \mathrm{~N} / \mathrm{mm}^{2}$, Modulus of Elasticity $\left(E_{c}\right)=5000 \sqrt{ }$ fck N$/ \mathrm{mm}^{2}$, Steel $-\mathrm{Fe}$ 415 grade, Yield stress $\left(f_{y}\right)=415 \mathrm{~N} / \mathrm{mm}^{2}$

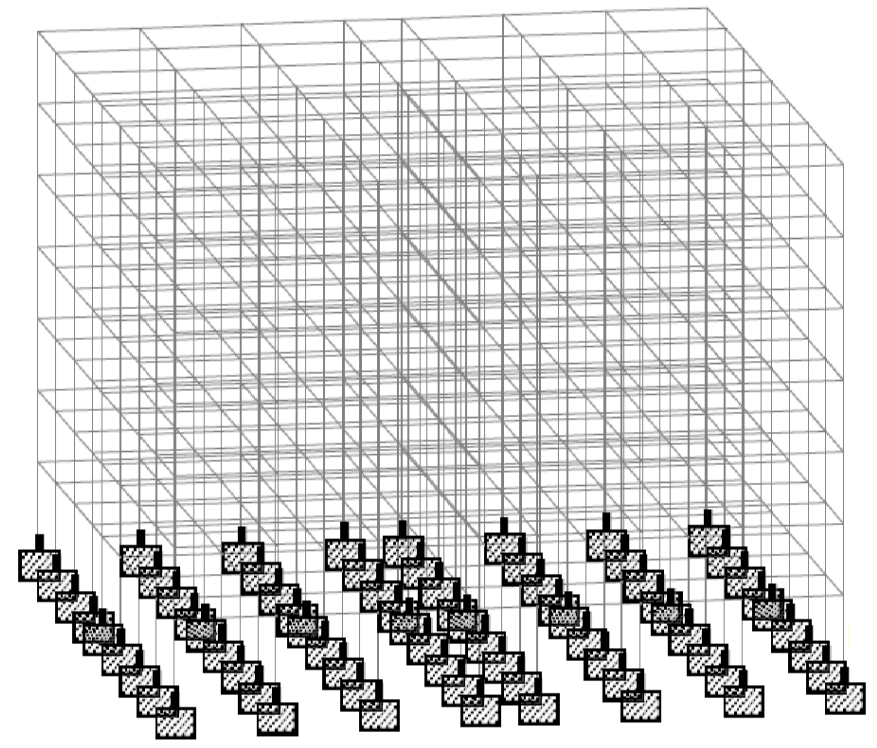

Figure 5 Building B21 modeled in STAAD Pro.
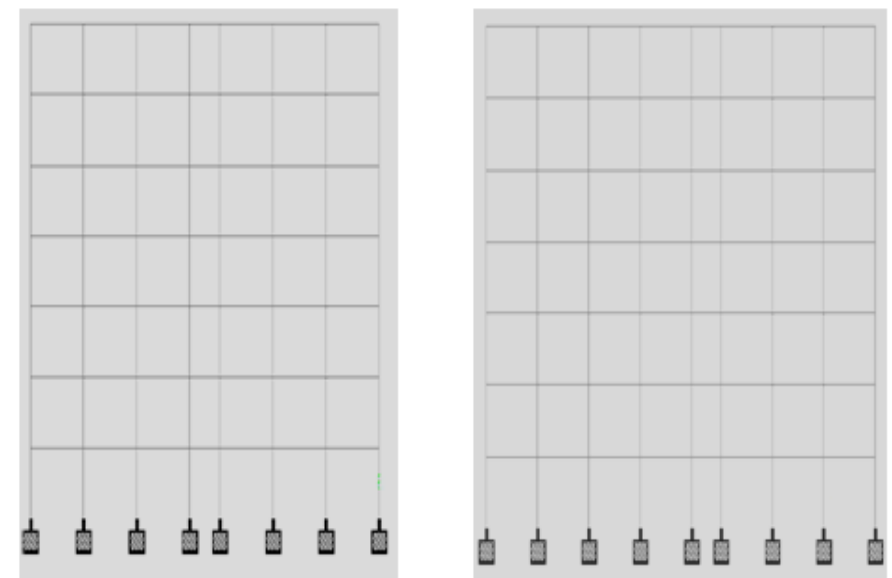

Figure $6 \mathrm{X}-\mathrm{Y}$ and Z-Y projections of Building B21

\section{RESULTS AND DISCUSSIONS}

Eigen value analysis is performed in order to obtain the natural modes of vibration of the towers. 


\subsection{Mode Shapes And Frequencies Of Towers M24}

\section{And M21}

In this analysis the overall mass and stiffness of a structure is used to find the various periods at which it will naturally resonate. Modal analysis of the tower structures is carried out to obtain natural frequency and mode shapes. Figure 7 shows the lowest six mode shapes and Table 7 shows natural frequencies of Tower M24. Figure 8 shows lowest six mode shapes and Table 8 shows lowest natural frequencies of Tower M21.

Table 7 Natural frequency of tower M24

\begin{tabular}{|l|l|l|}
\hline Mode & Frequency $(\mathrm{Hz})$ & Period $(\mathrm{sec})$ \\
\hline 1 & 5.013 & 0.199 \\
\hline 2 & 16.524 & 0.061 \\
\hline 3 & 17.445 & 0.057 \\
\hline 4 & 21.045 & 0.048 \\
\hline 5 & 22.758 & 0.044 \\
\hline 6 & 24.814 & 0.040 \\
\hline
\end{tabular}
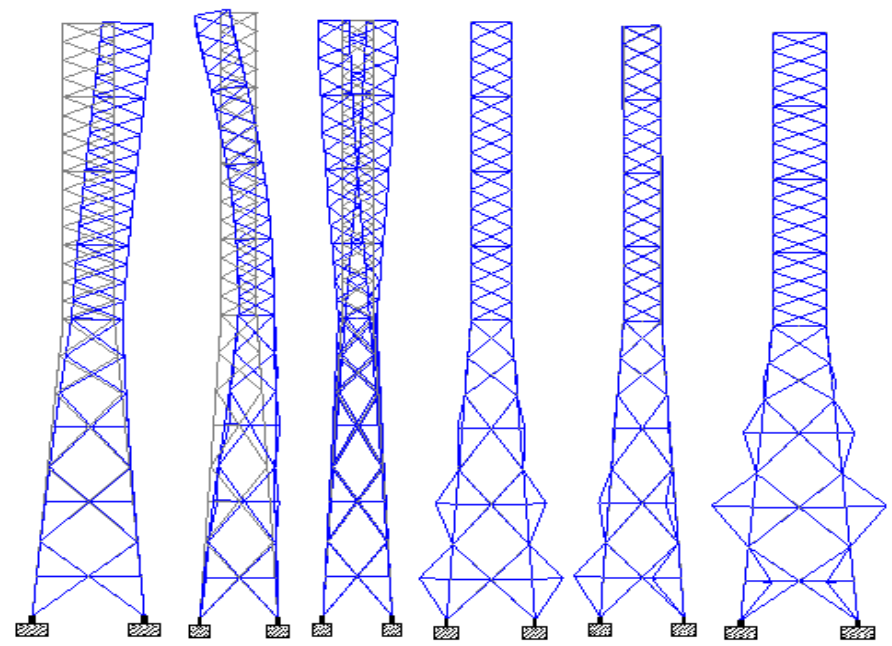

Figure 7 Lowest 6 natural frequencies and mode shapes of Tower M24

The fundamental sway mode is found at $5.013 \mathrm{~Hz}$. The fundamental torsional mode is found at a frequency of $17.445 \mathrm{~Hz}$. The number of mode shapes considered for modal superposition is chosen such as to include at least the lowest three sway modes of the tower, which spans up to 17.445 $\mathrm{Hz}$ in this example.

Table 8 Natural frequency of tower M21

\begin{tabular}{|l|l|l|}
\hline Mode & Frequency $(\mathrm{Hz})$ & Period $(\mathrm{sec})$ \\
\hline 1 & 6.682 & 0.150 \\
\hline 2 & 20.180 & 0.050 \\
\hline 3 & 20.630 & 0.048 \\
\hline 4 & 21.045 & 0.040 \\
\hline 5 & 22.900 & 0.044 \\
\hline 6 & 24.814 & 0.040 \\
\hline
\end{tabular}

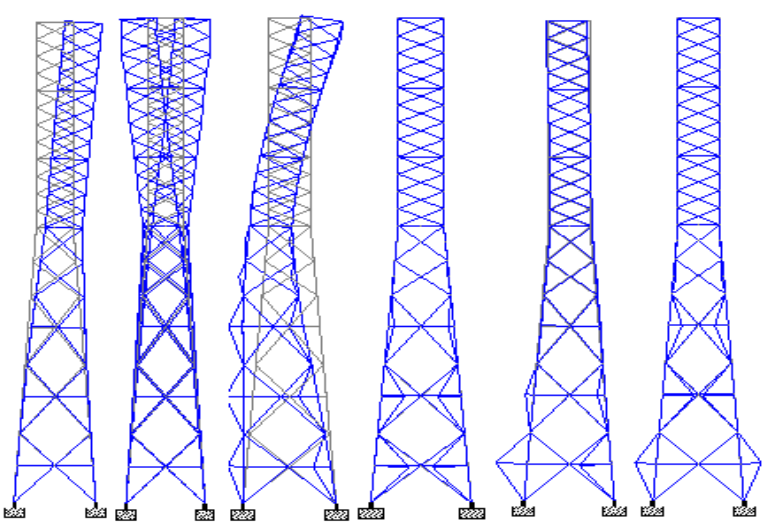

Figure 8 Lowest 6 natural frequencies and mode shapes of Tower M21

The fundamental sway mode is found at $6.671 \mathrm{~Hz}$. The fundamental torsional mode (Mode 4) appears at a frequency of $16.271 \mathrm{~Hz}$. The number of mode shapes considered for modal superposition is chosen such as to include at least the lowest three sway modes of the tower, which spans up to $13.6667 \mathrm{~Hz}$ in this example.

\subsection{Mode Shapes And Natural Frequencies Of Building B16}

Figure 9 shows the lowest six mode shapes and Table 9 shows natural frequencies of Building B16. As for the towers, the mode shape of Building B16 is calculated. The fundamental frequency is found at $1.363 \mathrm{~Hz}$ for the first sway mode in the $\mathrm{Y}$ direction. With these lowest 6 modes, an effective participating mass ratio of $90 \%$ is reached.

Table 9 Natural frequency of building B16

\begin{tabular}{|l|l|l|}
\hline Mode & Frequency $(\mathrm{Hz})$ & Period $(\mathrm{sec})$ \\
\hline 1 & 1.363 & 0.734 \\
\hline 2 & 1.840 & 0.544 \\
\hline 3 & 3.381 & 0.296 \\
\hline 4 & 4.269 & 0.234 \\
\hline 5 & 4.655 & 0.215 \\
\hline 6 & 4.949 & 0.202 \\
\hline
\end{tabular}
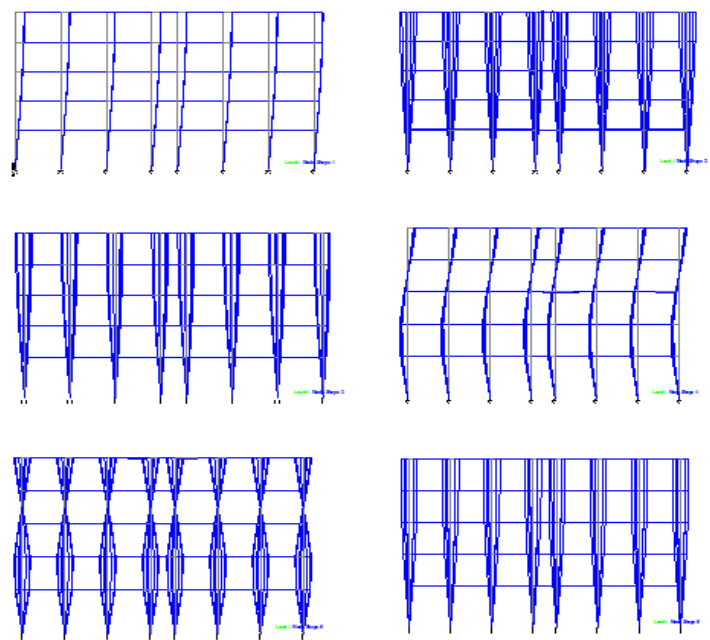

Figure 9 Lowest 6 natural frequencies and mode shapes of Building B16 


\subsection{Mode Shapes And Natural Frequencies Building B21}

Figure 10 shows the lowest six mode shapes and Table 10 shows natural frequencies of Building B21. An effective participating mass ratio of $81.844 \%$ is obtained at Mode 5 . The fundamental lateral frequency is found at $1.488 \mathrm{~Hz}$ for the sway in the $\mathrm{X}$ direction.

Table 10 Natural frequency of Building B21

\begin{tabular}{|l|l|l|}
\hline Mode & Frequency $(\mathrm{Hz})$ & Period $(\mathrm{sec})$ \\
\hline 1 & 1.488 & 0.672 \\
\hline 2 & 1.715 & 0.583 \\
\hline 3 & 2.939 & 0.418 \\
\hline 4 & 3.266 & 0.306 \\
\hline 5 & 4.157 & 0.241 \\
\hline 6 & 4.621 & 0.216 \\
\hline
\end{tabular}

In summary, the fundamental lateral frequencies of the tower models M24 and M21 are $5.013 \mathrm{~Hz}$ and $6.183 \mathrm{~Hz}$ respectively. Whereas, the building models B16 and B21 have $1.36 \mathrm{~Hz}$ and $1.233 \mathrm{~Hz}$ frequency respectively. For towers mounted on rooftops, the buildings frequencies will determine the frequency content of the excitation at the tower base. Therefore, both the buildings and the towers, considered separately as well as combined, are expected to be sensitive to earthquakes.

\subsection{Combined Tower-Building Models}

The towers are assumed to be mounted at the centre of roof of the buildings. This position minimizes torsional effects on the building as a whole and on the top portion, in particular. As for the interface roof-tower in the model, a stiff, triangular plate is fixed to the 4 main tower legs. Figure 11 shows the combined model and Table 11 shows the lowest frequencies of tower M24 on Building B16 and figure 12 shows corresponding mode shapes of the combined model (building B16 and tower M24).
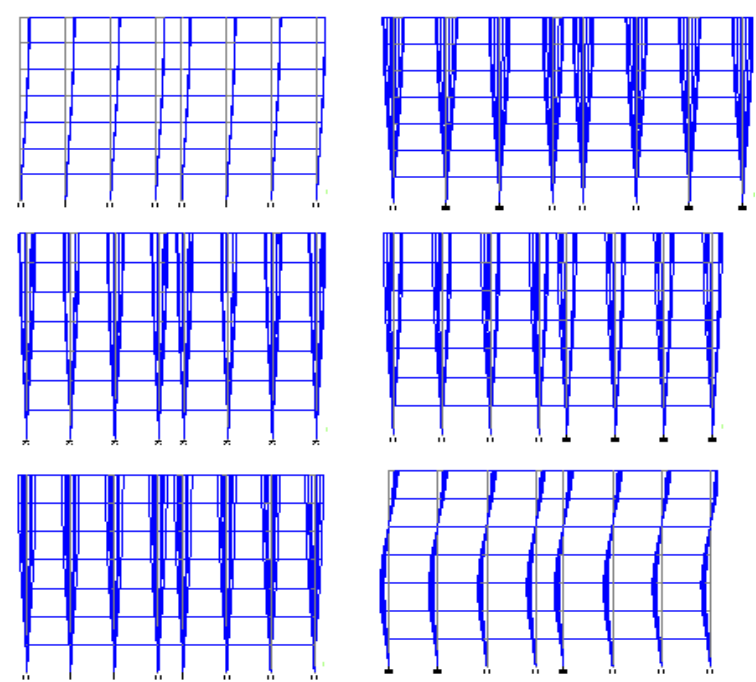

Figure 10 Lowest 6 natural frequencies and mode shapes of Building B21

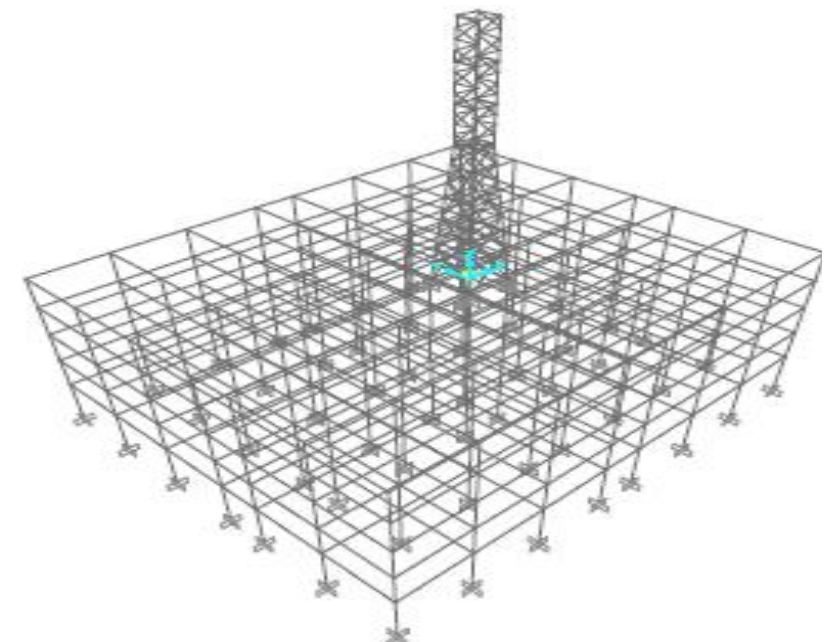

Figure 11 Combined model (Tower M24 on Building B16)

Table 11 Natural frequency of tower M24 on Building B16

\begin{tabular}{|l|l|l|}
\hline Mode & Frequency $(\mathrm{Hz})$ & Period $(\mathrm{sec})$ \\
\hline 1 & 1.359 & 0.736 \\
\hline 2 & 1.839 & 0.544 \\
\hline 3 & 3.363 & 0.297 \\
\hline 4 & 4.207 & 0.238 \\
\hline 5 & 4.570 & 0.219 \\
\hline 6 & 4.689 & 0.213 \\
\hline
\end{tabular}
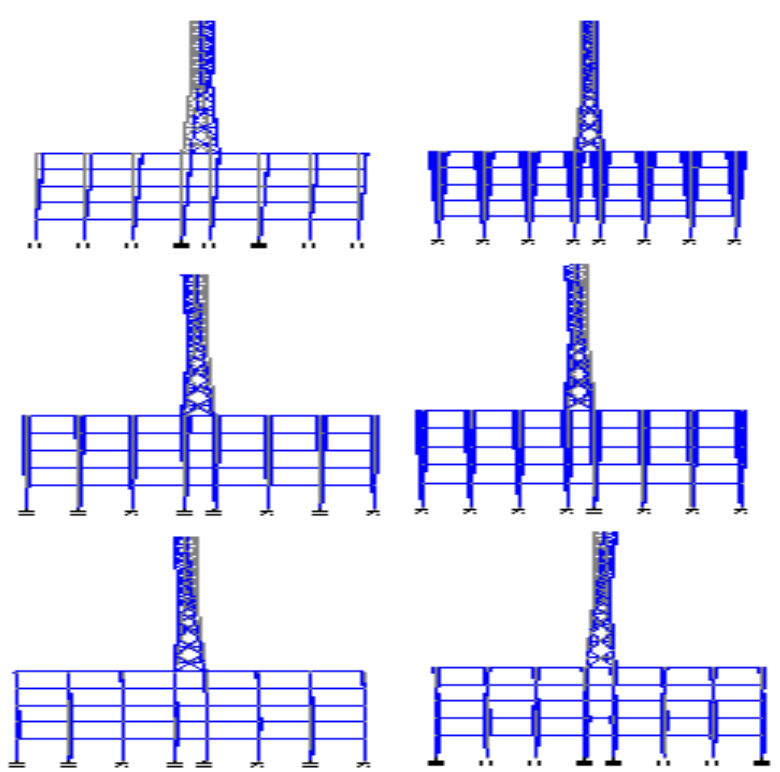

Figure 12 Lowest frequencies and corresponding mode shapes of the combined model (Tower M24 on Building B16)

For the four models studied, it was found that the presence of the tower has negligible influence on the lowest three sway modes and frequencies of the building, contributing to a slight shift in the lower range due to the added mass at roof level. As expected, the influence of the building on the sway modes of the towers is very important, whereas torsional modes are not affected. Results are shown in Table 12 for the lowest two sway and torsion modes of the towers. 


\section{Comparison of Axial Forces}

The axial forces of selected members were tabulated in Table 13 for leg, diagonal and horizontal members. Figure
12 to 14 shows the comparison plot of axial forces for leg, diagonal and horizontal members of roof top tower and ground towers for panel 1 and panel 2 .

Table 12 Comparison of natural frequencies $(\mathrm{Hz})$ of telecommunication towers

\begin{tabular}{|l|l|l|l|l|l|l|}
\hline Modes & $\begin{array}{l}\text { Tower M24 } \\
\text { on ground }\end{array}$ & $\begin{array}{l}\text { Tower M21 } \\
\text { on ground }\end{array}$ & $\begin{array}{l}\text { Tower M24 on } \\
\text { Building B16 }\end{array}$ & $\begin{array}{l}\text { Tower M24 on } \\
\text { Building B21 }\end{array}$ & $\begin{array}{l}\text { Tower M21 on Tower M21 on } \\
\text { Building B16 } \\
\text { Building B21 }\end{array}$ \\
\hline Sway 1 & 5.013 & 6.682 & 1.359 & 1.230 & 1.125 & 1.231 \\
\hline Torsion 1 & 17.445 & 20.180 & 1.839 & 1.449 & 1.433 & 2.289 \\
\hline Sway 2 & 16.524 & 20.630 & 3.363 & 2.279 & 2.330 & 1.449 \\
\hline Torsion 2 & 24.18 & 24.814 & 4.689 & 4.060 & 3.982 & 4.063 \\
\hline
\end{tabular}

Table 13 Axial Forces (KN) in Leg, Diagonal and Redundant members of Towers on ground and building top

\begin{tabular}{|l|l|l|l|l|l|l|l|}
\hline Member & Panel & $\begin{array}{l}\text { Tower M24 } \\
\text { on ground }\end{array}$ & $\begin{array}{l}\text { Tower M21 } \\
\text { on ground }\end{array}$ & $\begin{array}{l}\text { Tower M24 on } \\
\text { Building B16 }\end{array}$ & $\begin{array}{l}\text { Tower M21 on } \\
\text { Building B16 }\end{array}$ & $\begin{array}{l}\text { Tower M24 on } \\
\text { Building B21 }\end{array}$ & $\begin{array}{l}\text { Tower M21 on } \\
\text { Building B21 }\end{array}$ \\
\hline \multirow{2}{*}{ Main leg } & $\mathbf{1}$ & 380.783 & 304.587 & 434.732 & 350.289 & 434.732 & 350.289 \\
\cline { 2 - 9 } & $\mathbf{2}$ & 355.198 & 274.583 & 404.580 & 315.187 & 404.580 & 315.187 \\
\hline \multirow{2}{*}{ Diagonals } & $\mathbf{1}$ & 18.091 & 17.186 & 20.918 & 19.916 & 20.918 & 19.685 \\
\cline { 2 - 9 } & $\mathbf{2}$ & 14.128 & 13.793 & 16.519 & 16.154 & 16.519 & 16.154 \\
\hline \multirow{2}{*}{ Redundant } & $\mathbf{1}$ & 1.791 & 1.432 & 1.960 & 1.660 & 1.960 & 1.660 \\
\cline { 2 - 9 } & $\mathbf{2}$ & 2.261 & 1.772 & 2.586 & 2.046 & 2.584 & \\
\hline
\end{tabular}

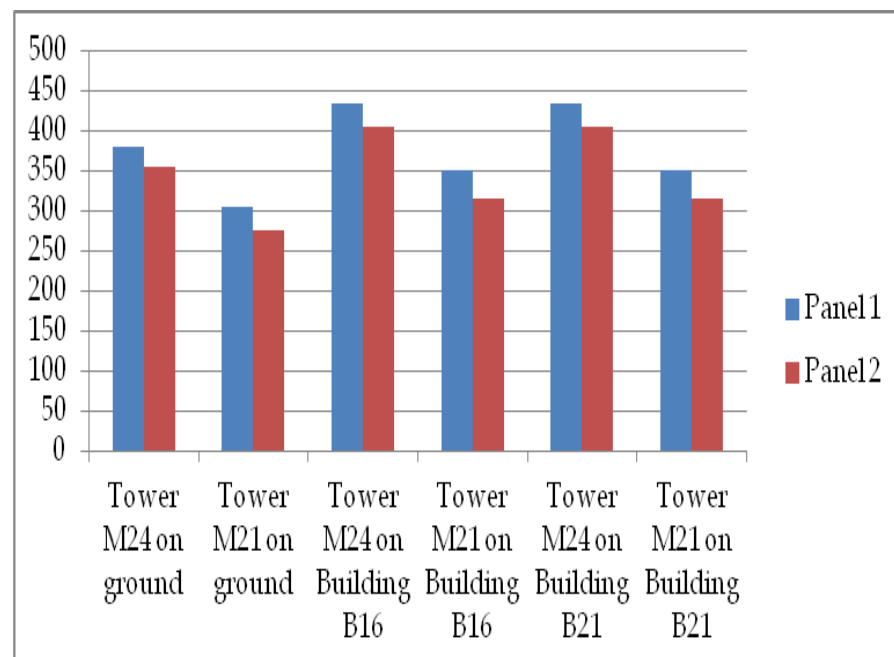

Figure 13 Comparison plots of axial forces for Main leg

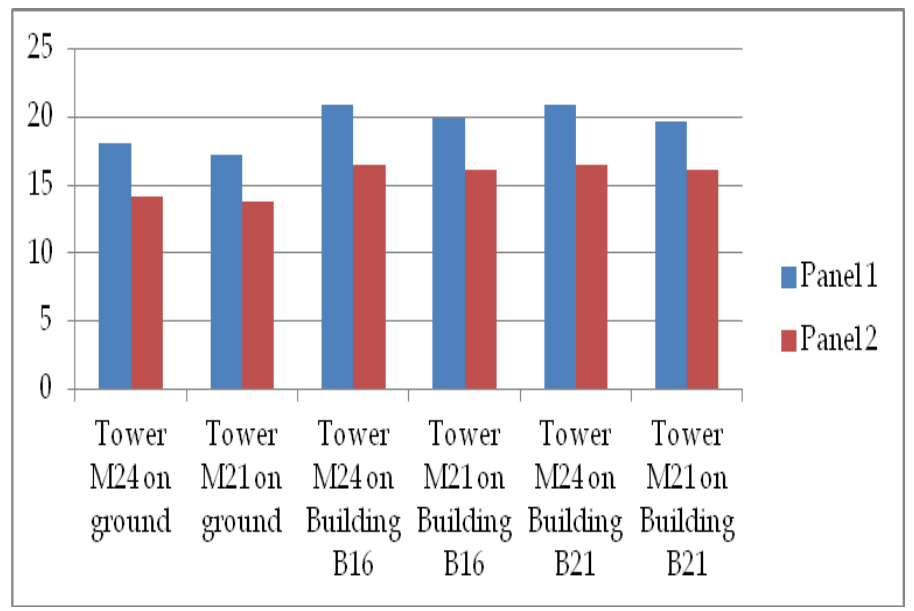

Figure 14 Comparison plots of axial forces for Diagonal members

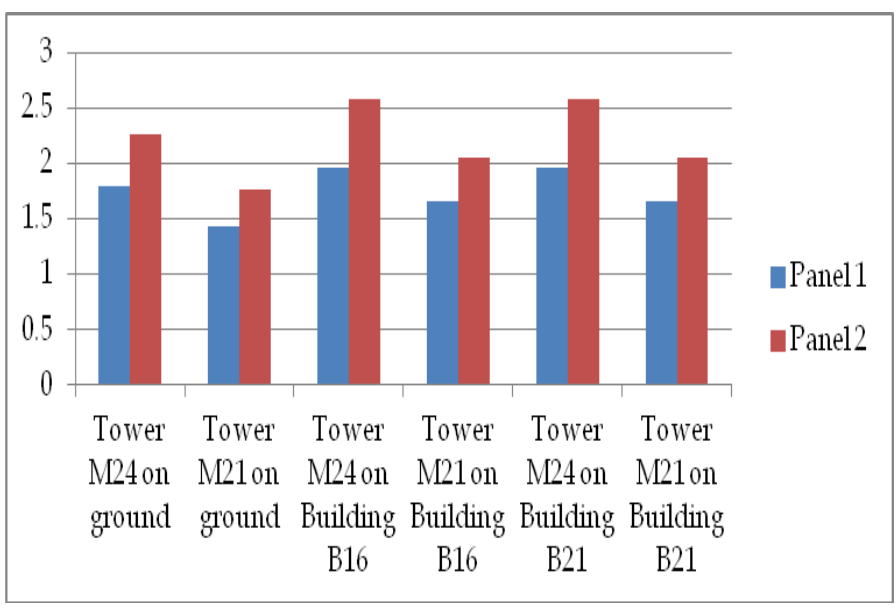

Figure 15 Comparison plots of axial forces for Redundant members

\section{CONCLUSIONS}

1. The presence of a normal size tower on the buildings does not have a noteworthy influence on the building frequencies and mode shapes, it is desirable to use a prediction of the roof acceleration based on the natural frequencies of the building alone. Though the natural frequencies of the towers are greatly affected by the flexible base provided by the building, it is essential to find a simple rational way to predict this frequency shift.

2. Tower with frequencies close to that fundamental sway mode will see its response much amplified. In a condition where the building's fundamental sway mode is not excited by the ground motion, the amplification of the motion at the rooftop is not as important unless there is coincidence with higher sway modes. It is also observed that the trend is similar for the two main input 
directions of the ground motion, indicating that there is not much coupling between the two main directions in the response of the roof at the tower base.

3. The design of roof top towers cannot be based on analytical results obtained for a similar configuration situated at ground level. As observed, the axial forces in rooftop tower are increased approximately by two to three times (max.) with respect to ground tower.

4. By increasing the stiffness of the host structure in both the directions ( $\mathrm{X}$ and $\mathrm{Y}$ ), the axial forces (tensile \& compression) in rooftop towers were increased by minimal amount of $5 \%$.

5. It can be concluded that the response in torsional modes were unaltered by the locations of the rooftop tower.

6. The results showed that the axial forces in all the tower members that were close to the antenna attachment points to the tower are noticeably high than those in the bare towers. Certainly, it is prominent that with use of latest digital communication systems, much smaller and lighter antennas are likely to be used which will significantly condense the mass effects of such antennas on the towers.

7. There is gradual decline in the natural frequency of the structure as the height of tower increases. This is as a result of the influence of mass as the height increases the mass starts to play predominant role than stiffness, there by dropping the natural frequency of the structure.

8. The vertical members are more important in taking the loads of the tower than the horizontal and diagonal member, the member supporting the antenna structures at higher elevation are expected to have large influence on the behaviour of the tower.

\section{REFERENCES}

[1] I.S. 802: Part 1: Sec: 1:1995: "Code of Practice for Use of Structural Steel in Over Head Transmission Line Towers-Materials and Loads.

[2] I.S. 802: Part 2: Sec: 1:1995: "Code of Practice for Use of Structural Steel in Over Head Transmission Line Towers-Permissible Stresses.

[3] I.S. 5613: Part 2: Sec: 1: 1989: Code of Practice for Design, Installation and Maintenance for Over Head Power Lines: Lines above $11 \mathrm{KV}$ And Up to And Including $220 \mathrm{KV}$ : Design.

[4] I.S. 5613: Part 2: Sec: 2: 1989: Code of Practice for Design, Installation and Maintenance for Over Head Power Lines: Lines above $11 \mathrm{KV}$ And Up to And Including $220 \mathrm{KV}$ : Installation and Maintenance.

[5] I.S. 875: Part 3: 1987: Code of Practice for Design Loads (other than Earthquake) for Buildings and Structures: Wind loads.

[6] Amiri G., Barkhordari M.A., Massah S. R., Vafaei M.R., (2007), "Earthquake Amplification Factors for Self-supporting 4-legged Telecommunication Towers", World Applied Sciences Journal.

[7] Amiri G., Massah S.R., (2007), "Seismic response of 4legged self-supporting telecommunication towers",
International Journal of Engineering Transactions B: Applications.

[8] Amiri G., Barkhordari M.A., Massah S.R., (2004), "Seismic Behaviour of 4-Legged Self-Supporting Telecommunication Tower", 13th World Conference on Earthquake Engineering, Canada.

[9] Amiri G., Boostan A., (2002), "Dynamic response of antenna-supporting structures", 4th Structural Specialty Conference of the Canadian Society for Civil Engineering.

[10] Amiri G., Azad A., (2002), "Seismic sensitivity of selfsupporting telecommunication masts", 12th European Conference on Earthquake Engineering, London.

[11] Galvez C, McClure G., (1995), "A simplified method for a seismic design of self-supporting lattice telecommunication towers". Proceedings of the 7th Canadian Conference on Earthquake Engineering, Montreal, Canada, pp 541-548.

[12] H.Siddhesha, 2010, "Wind analysis of Microwave Towers", International Journal of Applied Engineering Research, Dindigul, 1(3), pp 574-584.

[13] Khedr A., McClure G., (2000), “A simplified method for seismic analysis of lattice telecommunication towers", Canadian Journal of Civil Engineering.

[14] Khedr M.A, McClure G., (1999), "Earthquake amplification factors for self-supporting telecommunication towers", Canadian Journal of Civil Engineering.

[15] McClure G., Georgi L., Assi R, 2004, "Seismic considerations for telecommunication towers mounted on building rooftop", 13th World Conference on Earthquake Engineering, Vancouver, Canada.

[16] Mikus, J., (1994), "Seismic analysis of self-supporting telecommunication towers, M. Eng. Project Report G94-10. Department of Civil Engineering and Applied Mechanics, McGill University, Montreal, Canada. 